\title{
Synaptic Plasticity in the Cerebellar Cortex and its Role in Motor Learning
}

\author{
Masao Ito
}

\begin{abstract}
Synaptic plasticity plays a role in the learning capability of brain tissues. Long-term depression (LTD) of parallel fiber synapses in cerebellar Purkinje cells occurs when these synapses are activated in conjunction with climbing fiber synapses. Signal transduction mechanisms underlying LTD have recently been investigated extensively. It has also become apparent that climbing fiber signals encode errors in the motor performance of an animal. It is therefore hypothesized that learning proceeds in cerebellar tissues in such a way that error signals of climbing fibers act to depress by LTD those parallel fiber synapses responsible for the errors. The cerebellum contains a large number of corticonuclear microcomplexes. Each microcomplex is connected to an extracerebellar system and is presumed to endow the system with learning capability. The hypothesis accounts for the adaptation of the vestibuloocular reflex and probably also for other forms of motor and cognitive learning.

RÉSUMÉ: La plasticité synaptique du cortex cérébelleux et son rôle dans l'apprentissage moteur. La plasticité synaptique joue un rôle comme élément mnésique dans la capacité d'apprentissage des tissus du cerveau. Il se produit une dépression à long terme (DLT) des synapses des fibres parallèles dans les cellules de Purkinje du cervelet lorsque ces synapses sont activées de concert avec les synapses des fibres grimpantes. Les mécanismes de la transduction du signal sous-jacents à la DLT ont été investigués récemment. Il est devenu évident que les signaux provenant des fibres grimpantes enregistrent des erreurs dans la performance motrice d'un animal. Nous émettons l'hypothèse que, dans les tissus cérébelleux, l'apprentissage procède de façon à ce que les signaux erronés des fibres grimpantes provoquent une dépression par DLT des synapses des fibres parallèles responsables des erreurs. Le cervelet contient un grand nombre de microcomplexes corticonucléaires. Chaque microcomplexe est relié à un système extracérébelleux et on présume qu'il confère au système une capacité d'apprentissage. Cette hypothèse explique bien l'adaptation du réflexe vestibulooculaire et probablement d'autres formes d'apprentissage moteur et même un certain type d'apprentissage mental.
\end{abstract}

Can.J. Neurol. Sci. 1993; 20 (Suppl. 3): S70-S74

It has been a long-standing question whether the cerebellum is capable of learning. In earlier studies, learning capability of the cerebellum was proposed based on marked restoration of motor function after partial lesioning of the cerebellum. ${ }^{1-3}$ In recent years, two lines of evidence have been presented. First, a unique type of synaptic plasticity, long-term depression (LTD), was found to occur in the cerebellar cortex. Second, simple learning functions such as adaptation of the vestibuloocular reflex (VOR), eye-blink classic conditioning, or adaptation of arm tracking were demonstrated to involve certain parts of the cerebellum. These two lines of evidence encourage efforts to develop a general concept of cerebellar learning applicable to the entire cerebellum, which is implicated not only in motor and autonomic, but also in certain mental functions.

In this article, recent evidence for LTD and VOR adaptation will be briefly reviewed, and reasons for controversies so far raised will be given. General principles of cerebellar learning will then be derived from control theory views of VOR adaptation.

\section{LONG-TERM DEPRESSION}

A prominent feature of the cerebellar cortical circuitry is that each Purkinje cell receives two distinct types of excitatory input from parallel fibers and climbing fibers in a contrasting manner of convergence: while a Purkinje cell receives synapses from numerous parallel fibers, each having a weak effect, it receives synapses from only one climbing fiber which exerts a powerful effect on Purkinje cell dendrites. ${ }^{4}$ Around 1970, theorists viewed this peculiar structure as representing Hebb's plasticity rule, ${ }^{5}$ and hypothesized that parallel fiber synapses will be either enhanced $^{6}$ or depressed $^{7}$ when these synapses are activated in conjunction with climbing fiber synapses. Such synaptic plasticity endows the cerebellar circuitry with learning capability. After struggling for more than 10 years, researchers discovered that long-term depression (LTD) actually occurs in Purkinje cells. ${ }^{8}$ The occurrence .of LTD has been confirmed by various recording and stimulating techniques both in vivo $o^{9.10}$ and in vitro. ${ }^{11-14}$ 
Possible reasons as to why LTD was overlooked in earlier studies have already been accounted for. ${ }^{15}$ The most common reason appears to be that extracellular recording of mass field potentials is an inefficient index of LTD,${ }^{9}$ in spite of the fact that it effectively reflects long-term potentiation in the hippocampus. Complex receptor messenger reactions underlying LTD (see below) are another possible cause for the failure, because the occurrence of LTD could be blocked at the site of these chain reactions under varied experimental conditions.

\section{Receptors and Messengers Involved in LTD}

The essential process of LTD is persistent desensitization of an AMPA-selective subtype of glutamate receptors which mediate parallel fiber-Purkinje cell transmission, as reviewed elsewhere. ${ }^{16.17} \mathrm{Ca}^{2+}$ ions, nitric oxide or its related substance, cyclic GMP and protein kinases $C$ and $G$ have been implicated in messenger processes underlying LTD. ${ }^{14,18,19}$ An important recent outcome is that hemoglobin blocks LTD without affecting other processes in the cerebellar cortex ${ }^{18,20}$ Knowledge of function at the molecular levels thus provides a tool for manipulating LTD (see below).

\section{Coding of Error Signals by Climbing Fibers}

Climbing fibers play a leading role in induction of LTD. Hence, the information encoded in climbing fiber signals is important when one interprets functional roles of LTD. Around 1970 , suggestions were made for various reasons that climbing fiber impulses represent a "comparison between central command and peripheral signals", 21 "instruction of control errors",,22 and "misperformance in pattern recognition". 7 These statements have similar implications, namely that climbing fibers monitor the performance of a system in which given cerebellar circuitry plays a role, and that climbing fibers inform Purkinje cells about control errors due to misperformance of the system. This postulate has now gained experimental support from research on various forms of cerebellar controls such as VOR (see below), smooth pursuit eye movement, ${ }^{23}$ or arm trajectory formation. ${ }^{24}$

\section{Simple Forms of Cerebellar Learning}

\section{Adaptation of the Vestibuloocular Reflex (VOR)}

The cerebellar flocculus receives vestibular signals via mossy fibers, which are relayed to parallel fibers. The flocculus also receives retinal signals via climbing fibers. ${ }^{25}$ Floccular Purkinje cells directly inhibit relay cells of the VOR. ${ }^{26}$ Thus, the flocculus hypothesis that flocculus controls VOR adaptively by referring to retinal errors reflecting inadequacy of the VOR performance has been proposed. ${ }^{27.28}$ The demonstration that VOR adaptation occurs under conflicting visual-vestibular stimuli ${ }^{29}$ provided a means for experimentally testing the hypothesis.

Two lines of evidence have been collected to support the hypothesis in a series of experiments on rabbits. ${ }^{15,28}$ l) Lesioning of the flocculus or interruption of the climbing fiber afferents abolishes the VOR adaptation. 2) Responses of flocculus Purkinje cells to head rotation alter in parallel with adaptive modification of VOR.

Arguments against the first line of evidence state that a flocculus lesion can impair VOR adaptation even if the flocculus is not the site of adaptation, interfering with the dynamic characteristics of the VOR or interrupting a pathway to an adaptive center via the flocculus. Contention against the second line of evidence states that responses of flocculus Purkinje cells in monkeys are inconsistent with the flocculus hypothesis. ${ }^{30}$ However, some recent findings refute these objections. 1) Subdural application of hemoglobin to the flocculus abolished VOR adaptation in both rabbits and a monkey. ${ }^{31}$ Since hemoglobin blocks LTD but does not affect the dynamic characteristics of eye movements, there is no evidence that hemoglobin abolishes VOR adaptation for any reason other than LTD blockade. 2) The area of monkey cerebellum which was regarded as an anterior portion of the flocculus in previous experiments, ${ }^{23}$ has been identified as the ventral paraflocculus. ${ }^{32}$ In the actual monkey flocculus, which is located more caudally, Purkinje cell behavior conforms to the flocculus hypothesis. ${ }^{33}$

In addition to these experimental approaches, VOR adaptation was reproduced by computer simulation using an adaptive filter model of the flocculus. ${ }^{34}$ Hence, one can support the flocculus hypothesis with a high level of certainty.

\section{Other Forms of Cerebellar Learning}

Eye-blink conditioning, ${ }^{35}$ locomotive adaptation, ${ }^{36,37}$ arm trajectory formation ${ }^{24.38}$ and other forms of learning have been investigated intensively in the past two decades. Compared to VOR, the neural system executing these tasks have more complicated structures, so that there is still much to be clarified before we understand the neural mechanisms of these tasks in connection with LTD and cerebellar learning. It is essential to identify the cerebellar area specifically involved with each task under testing, since ignorance of the fine microzonal structure of the cerebellum where each elongated microzone is only a fraction of a millimeter in width, ${ }^{39}$ has often been the cause of confusion when physiologically identifying the functional representation of Purkinje cells.

\section{Principles of Cerebellar Learning}

\section{Adaptive Feedforward Control}

VOR is a typical feedforward control system. Due to lack of feedback, the system has no means for immediately correcting its erroneous performance. Once deviated from its proper working range, its performance remains deviated unless the system corrects its performance through an adaptive mechanism. The author's assertion is that the flocculus is equipped with an errorcoding system of climbing fibers and such an adaptive mechanism for VOR. ${ }^{22,27}$ It may be that the flocculus detects retinal errors that reflect misperformance of VOR, and that it accordingly alters the dynamics of VOR so as to minimize the errors. Such adaptation represents the simplest form of learning. A similar principle seems to apply even when feedback is present, but ineffective within a certain working range, for example, at high frequency of movement. Virtually all reflexes, either somatic or autonomic, are endowed with adaptability by the cerebellum so that their dynamics are readjusted according to environmental change. It is believed that, without cerebellum, a reflex cannot match its operation to ever-changing body conditions.

If a feedforward system operates perfectly, its controller must bear dynamics $(1 / G)$ inversely equal to the dynamics of the control object (G). Then, the output of the system is equated to instruction to the system (Figure 1A). The task of the flocculus can be specified as adjusting the dynamics of the controller of the VOR, including the labyrinth, vestibular nuclei and flocculus, 
to be inversely equal to the dynamics of the control object including motoneurons, extraocular muscles and eyeballs (Figure 1B).

To generalize, a cerebellar corticonuclear microcomplex (CNMC) including a microzone of the cortex and a related small group of cerebellar or vestibular nuclear cells, is conceived as a functional unit of the cerebellum equipped with adaptive control mechanisms. ${ }^{40}$

\section{Model Formation}

A prominent feature of the adaptive system is its capability to form a model. The author previously proposed that a CNMC is inserted into a voluntary motor system as a model of a control object. ${ }^{22.40}$ Motor command signals generated by the cerebral cortex are sent to both the skeletomotor system to be controlled and a CNMC (Figure 2A). Output from either the skeletomotor system or the CNMC is fed back to the cerebral cortex, the former through a sensory system and the latter through an internal neuronal connection (Figure 2A). While movement is practiced using external feedback, the CNMC is adjusted so that internal feedback allows precise operation of the system even without external feedback. The cerebrocerebellar communication loop through the motor cortex and the paravermis of the cerebellum is consistent with this control scheme.

Another control scheme for voluntary movement has been proposed. ${ }^{41}$ A CNMC can be inserted in parallel with the cerebral controller, both acting on the same skeletomotor system (Figure 2B). This scheme is consistent with anatomical connections through the cerebral association cortex and cerebellar hemisphere. ${ }^{40}$ In this scheme, the CNMC develops dynamics

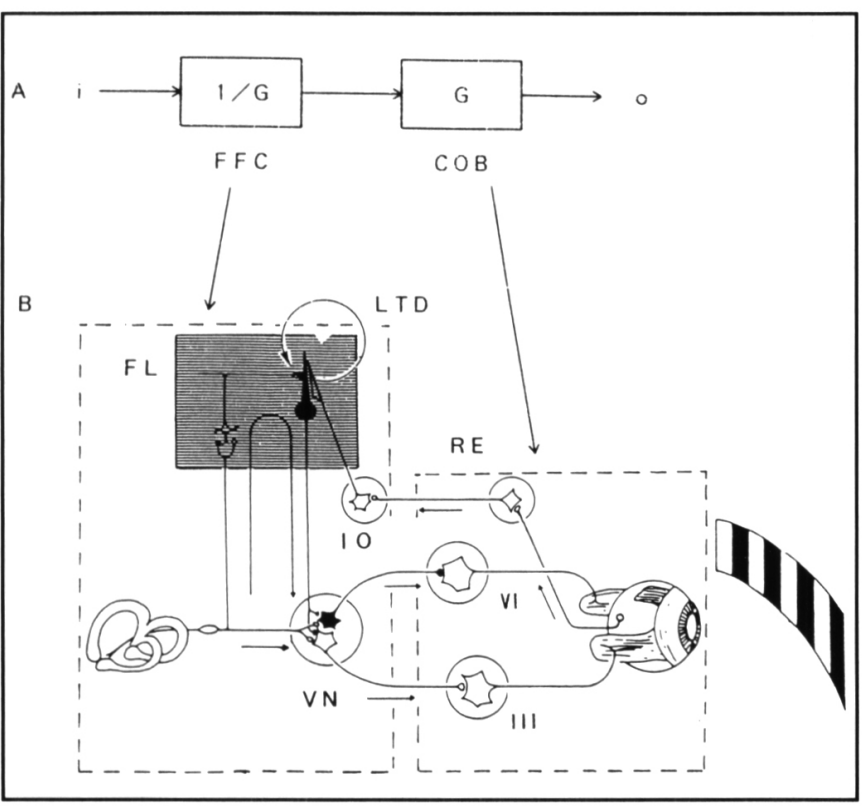

Figure I-Neuronal circuitry and control system structure of the flocculo-vestibulo-ocular system. A general structure of a feedforward control system. FFC feedforward controller. $C O B$ control object. $i$ input. o output. $G$ dynamics of $C O B . / / G$ dynamics of $F F C$. B neuronal circuitry structure of the vestibuloocular reflex arc. $I I I, V I$ oculomotor and abducens cranial nuclei. IO inferior olive. $V N$ vestibular nucleus. FL flocculus. RE retinal error. Note that inhibitory neurons and their processes are black, while excitatory ones are white. Control system structure is indicated by comparison with $A$. which are the inverse of the skeletomuscular system, just as the flocculo-vestibular system does in controlling VOR.

In a simulation study by Kawato et al., ${ }^{41}$ both of the above two schemes are incorporated in a robotic system as mutually complementary. It was recognized that the robot learns arm movement for any trajectory by practicing for only one set of trajectories. What is actually learned is not the trajectory, but the dynamics or inverse dynamics of the arm to be moved.

This situation distinguishes sharply between cognitive learning and motor learning. That which is acquired in motor learning is not a specific bit of information that can be declared, as in cognitive learning. Instead, it is the dynamics or inverse dynamics of a control object such as an arm or a leg. Motor learning is usually referred to as "procedural memory" against "declarative memory in cognitive learning", but "dynamics memory" may better apply to cerebellar learning.

\section{Mental Model}

Involvement of the cerebellum in mental activity has been suggested based on clinicopathological evidence. ${ }^{42}$ The control

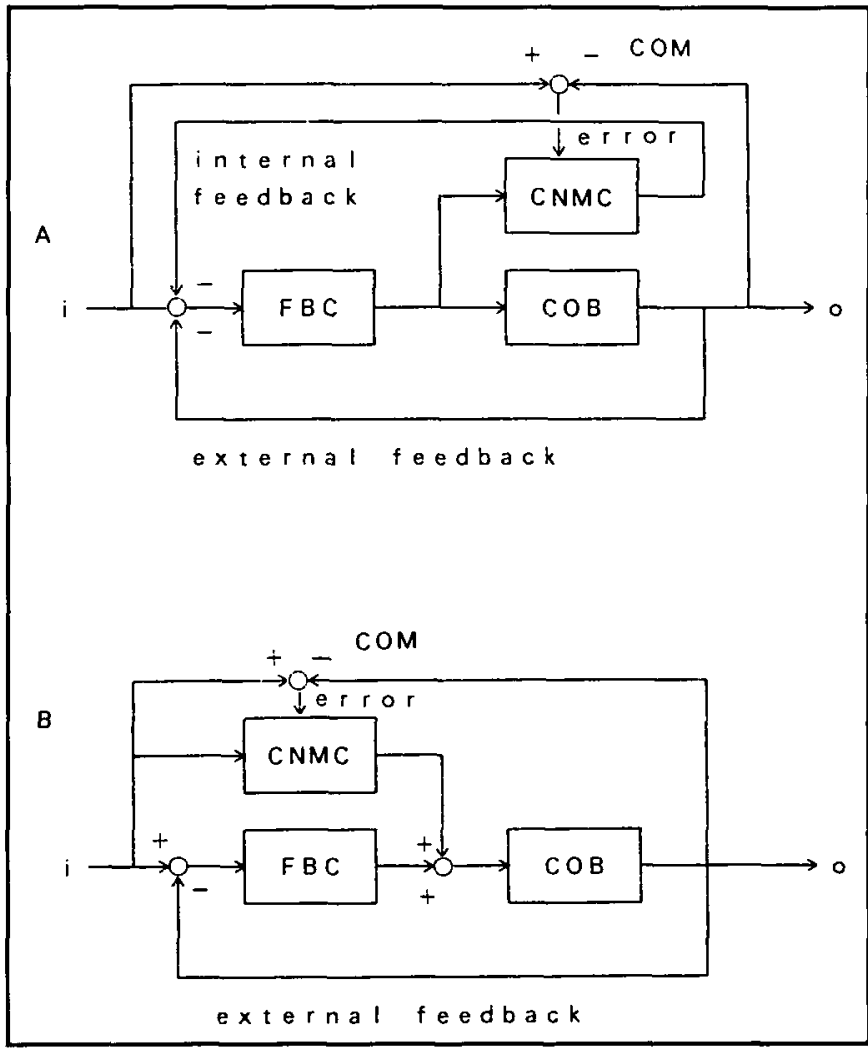

Figure 2 - Schemes for learning of voluntary movement control. A dynamics model scheme. A cerebellar corticonuclear microcomplex (CNMC) is assumed to consist of an internal feedback loop which is to be adjusted according to control errors. In this scheme, learning shifts the dominant mode of control from feedback to feedforward by replacing the external feedback by the internal feedback. COM comparator. $F B C$ feedback controller. $B$ inverse dynamics model scheme. CNMC is assumed to provide an adaptive feedforward controller. Learning shifts the dominance from feedback control by the cerebral cortex $(F B C)$ to feedforward control by the cerebellum (CNMC). In voluntary motor control, $C O B$ in $B$ will be provided by a skeletomotor system, and in mental control, by a cerebral cortical area. 
schemes represented in Figure 2 are so general that they can be applied to any combination of a feedback controller and a control object. Since the cerebellar hemisphere and cerebral association cortex are likely to be involved in mental control, Figure $2 \mathrm{~B}$ would apply better than Figure 2A in this case. In mental control, a control object may be provided by an idea or a concept instead of an arm or a leg, which is represented in a cerebral cortical area. A feedback controller may also be provided by an area of the cerebral cortex. In this situation, a CNMC provides a model of an idea or a concept to be manipulated by the controller area of the cerebral cortex. ${ }^{43}$ This model may somehow correspond to the view of the psychologically proposed "mental model".44

Figure 2 thus represents certain features of thought. After repeated trials, a thought becomes automatic and is exerted without much conscious concern. Arithmetic counting in a learned child appears to be conducted in such a way. Consistent with this postulate, noninvasive measurements have revealed significantly enhanced local blood flow in the cerebellar hemispheres during counting, silent imaging of movement ${ }^{45}$ or a certain type of language activity. ${ }^{46}$

\section{Comments}

The postulate of learning capability of the cerebellum is now supported by three lines of research on 1) LTD, 2) VOR adaptation, and 3) control system theories of the cerebellum. Unique and characteristic features of cerebellar learning, distinct from cognitive learning, have become apparent through these studies.

It is important to continue these three lines of research in order to uncover further details of cellular and molecular processes of LTD, and to confirm the involvement of LTD not only in VOR adaptation but also in other forms of motor learning such as eye-blink classic conditioning, postural and locomotive adaptation, recalibration of saccadic eye movements, and voluntary limb movements. It is also important to substantiate the postulate of cerebellar mental control by experimental as well as theoretical approaches.

\section{REFERENCES}

1. Flourens P. Recherche experimentales sur les proprietes et les fonctions du systeme nerveux dans les animaux vertebrés. Edition 2 Baillière, Paris 1842.

2. Luciani L. Il cervelletto: Nuovi studi di fisiologia normale et pathologica. Le Monnier, Florence 1891.

3. Dow RS, Moruzzi G. The Physiology and Pathology of the Cerebellum. University of Minnesota Press. Minneapolish 1958.

4. Eccles JC, Ito M, Széntagothái J. The Cerebellum as a Neuronal Machine. Berlin: Springer-Verlag 1967.

5. Brindley GS. The use made by the cerebellum of the information that it receives from sense organs. IBRO Bull 1964; 3: 80 .

6. Marr D. A theory of cerebellar cortex. J Physiol (Lond) 1969; 202: 437-470.

7. Albus JS. A theory of cerebellar function. Math Biosci 1971; 28: $167-171$.

8. Ito $M$, Sakurai $M$, Tongroach P. Climbing fibre-induced depression of both mossy fibre responsiveness and glutamate sensitivity of cerebellar Purkinje cells. J Physiol (Lond) 1982; 324: 113-145.

9. Ito $M$, Kano $M$. Long-lasting depression of parallel fiber-Purkinje cell transmission induced by conjunctive stimulation of parallel fibers and climbing fibers in the cerebellar cortex. Neurosci Lett 1982; 33: 253-258.

10. Ekerto C-F, Kano M. Long-term depression of parallel fibre synapses following stimulation of climbing fibres. Brain Res $1985 ; 341: 357-360$.
11. Sakurai M. Synaptic modification of parallel fiber-Purkinje cell transmission in in vitro guinea pig cerebellar slices. J Physiol (Lond) 1987; 394: 463-480.

12. Crepel $F$, Krupa M. Activation of protein kinase $C$ induces a longterm depression of glutamate sensitivity of cerebellar Purkinje cells: an in vitro study. Brain Res 1988; 458: 397-401.

13. Hirano T. Differential pre- and post-synaptic mechanisms for synaptic potentiation and depression between a granule cell and a Purkinje cell in rat cerebellar culture. Synapse 1991; 7: 321323.

14. Linden DJ, Dickinson MH, Smeyne M, Connor JA. A long-term depression of AMPA currents in cultured cerebellar Purkinje neurons. Neuron 1991; 7: 81-89.

15. Ito $M$. The long-term depression. Ann Rev Neurosci 1989; 12: 85102.

16. Ito $M$. The cellular basis of cerebellar plasticity. Cur Opin Neurobiol 1991; 1: 616-620.

17. Crepel F, Ardinat E. Excitatory amino acid receptors of cerebellar Purkinje cells: development and plasticity. Progr Biophys Mol Biol 1991; 55: 31-46.

18. Ito $M$, Karachot $L$. Messengers mediating long-term densensitization in cerebellar Purkinje cells. NeuroReport 1990; 1: I29-132.

19. Crepel F, Jaillard D. Protein kinases, nitric oxide and long-term depression of synapses in the cerebellum. NeuroReport 1990; 1 : 133-136.

20. Shibuki K, Okada D. Endogenous nitric oxide release required for long-term synaptic depression in the cerebellum. Nature 1991; 349: 326-328.

21. Miller S, Oscarsson O. Termination and functional organization of spinocerebellar paths. In: Fields WS, Willis WD, eds. Cerebellum in Health and Disease. St. Louis: WH Green Inc. 1970: 172-200.

22. Ito M. Neurophysiological aspects of the cerebellar motor control system. Int J Neurol 1970; 7: 162-176.

23. Stone LS, Lisberger SG. Visual responses of Purkinje cells in the cerebellar flocculus during smooth-pursuit eye movements. I. Simple spikes. J Neurophysiol 1990; 63: 1241-126I.

24. Wang J-J, Kim JH, Ebner JT. Climbing fiber afferent modulation during a visually guided multi-joint arm movement in the monkey. Brain Res 1987; 410: 323-329.

25. Maekawa K, Simpson Jl. Climbing fiber responses evoked in vestibulo-cerebellum of rabbit from visual system. J Neurophysiol 1973; 36: 649-666.

26. Ito M, Highstein SM, Fukuda J. Cerebellar inhibition of the vestibulo-ocular reflex in rabbit and cat and its blockage by picrotoxin. Brain Res 1970; 17: 524-526.

27. Ito M. Neural design of the cerebellar motor control system. Brain Res 1972; 40: 81-84.

28. Ito M. Cerebellar control of the vestibulo-ocular reflex - around the flocculus hypopthesis. Ann Rev Neurosci 1982; 5: 275-296.

29. Gonshor A, Melvill-Jones GM. Extreme vestibulo-ocular adaptation induced by prolonged optical reversal of vision. J Physiol (Lond) 1976; 256: 381-414

30. Miles F, Fuller JH, Braitman DJ, Dow BM. Long-term adaptive changes in primate vestibuloocular reflex. III. Electrophysiological observations in flocculus of normal monkeys. J Neurophysiol 1980; 43: 1437-1476.

31. Nagao S, Ito M. Subdural application of hemoglobin to the cerebellar flocculus blocks adaptation of the vestibuloocular reflex. NeuroReport 1991; 2: 193-196.

32. Gerrits NM, Voogd J. The topographical organization of climbing and mossy fiber afferents in the flocculus and the ventral paraflocculus in rabbit, cat and monkey. Exp Brain Res 1989; 17: 26-29.

33. Nagao S. Different roles of flocculus and ventral paraflocculus for oculomotor control in the primate. NeuroRepor 1992; 3: 13-16.

34. Fujita M. Simulation of adaptive modification of vestibuloccular reflex with an adaptive filter model of the cerebellum. Biol Cybern 1982; 45: 207-214.

35. Thompson RF. The neurobiology of learning and memory. Science 1987; 233: 941-947.

36. Armstrong DM, Edgley SA. Discharge of Purkinje cells in the paravermal part of the cerebellar anterior lobe during locomotion in the cat. J Physiol (Lond) 1984; 352: 403-424. 
37. Matsukawa T, Udo M. Responses of cerebellar Purkinje cells to mechanical perturbations during locomotion of decerebrate cats. Neurosci Res 1985; 2: 393-398.

38. Gilbert PFC, Thach WT. Purkinje cell activity during motor learning. Brain Res 1977; 128: 309-328.

39. Oscarsson O. Functional units of the cerebellum - sagittal zones and microzones. Trends Neurosci 1979; 2: 143-145.

40. Ito M. The Cerebellum and Neural Control. New York: Raven Press 1984.

41. Kawato M, Furukawa K, Suzuki R. A hierarchical neural network model for control and learning of voluntary movement. Biol Cybern 1987; 57: 169-185.
42. Leiner HC, Leiner AL, Dow RS. Does the cerebellum contribute to mental skills? Behav Neurosci 1986; 100: 443-453.

43. Ito M. A new physiological concept of cerebellum. Rev Neurol (Paris) 1990; 146: 564-569.

44. Johnson-Laird PN. Mental Model. Cambridge Univ Press 1983.

45. Ingvar D. On ideation and "Ideography". In: Eccles JC, Creutzfeld $O$, eds. Principles of Design and Operation of the Brain. Berlin: Springer-Verlag 1991: 433-458.

46. Peterson SE, Fox PT, Posner MI, Mintun M, Raicle ME. Positron emission tomographic studies of the processing single words. J Cogn Neurosci 1990; 1: 153-170. 